\title{
Enhancing the Security of Vehicles and the Work of the DVLA Using GSM/SMS Technologies
}

\author{
Abeo Timothy Apasiba \\ School of Applied Science \\ Dept. of Computer Science \\ Tamale Polytechnic \\ Tamale, Ghana
}

\author{
J. B. Hayfron-Acquah \\ College of Science \\ Dept. of Computer Science \\ Kwame Nkrumah \\ University of \\ Science and Technology \\ Kumasi, Ghana
}

\author{
J. K. Panford \\ College of Science \\ Dept. of Computer Science \\ Kwame Nkrumah \\ University of \\ Science and Technology \\ Kumasi, Ghana
}

\author{
Michael Asante \\ College of Science \\ Dept. of Computer Science \\ Kwame Nkrumah \\ University of \\ Science and Technology \\ Kumasi, Ghana
}

\begin{abstract}
Vehicle theft is seen as occurring almost on daily basis. From the survey carried out for this research, over 90 percent of respondents testified to its existence. This research took a closer look at collaborations of Driver and Vehicle Licensing Authority and the Security Services in combating this crime. It also sought the readiness of vehicle owners, DVLA and Ghana Police Service to embrace technology integration.

A critical look at vehicle security in terms of its theft related problems, the integration of GSM/SMS technology into the Driver and Vehicle Licensing Authority Registration Database, making it easily accessible by the Security Services like the Ghana Police Service for quick and easy verification of driver or vehicle license status as well as the genuineness in relation to the ownership, in the fight against vehicle theft is very vital. Security personnel can send an SMS to the proposed system and instantly get reply containing significant particulars of the Vehicle and the owner.
\end{abstract}

Keywords: Vehicle Security; Verification; Database; DVLA; GSM; License; SMS Technology; Security service

\section{INTRODUCTION}

Vehicle theft and crime are fast becoming a canker in Ghana. The very nature of the crime and the relatively large sums of money involved in investing in vehicles makes it worse than petty theft. Car snatchers are constantly finding newer ways of evading car owners and the law. Vehicle crime is not limited to car snatching alone; more common incidents include driving without license, driving a car using the wrong type of, such as using a privately registered vehicle for commercial purposes or driving a heavy duty vehicle where a high level license is required.

From the previous readings and knowledge, the use of technology to fight vehicle theft and crime remains a largely untapped area especially in Ghana. This study looked at ways of using technology to combat car crime and theft. Further make recommendations have also been made on a specific but appropriate technology.

A “Ghana 2011 OSAC Crime and Safety Report” (2011) outlined the overall crime and safety situation in Ghana. In this report, the US Department of State's Bureau of Diplomatic Security has rated Ghana as a high crime threat post. It is indicated that vehicle crime in Ghana is a major concern. Using Nigeria as a case study, Bassey et al (2010) found out that a large percentage of stolen vehicles from Nigeria find their ways into neighboring countries including Ghana and vice versa. All these stolen vehicles with foreign registration numbers find their ways through the borders into Ghana or Nigeria for re-registration at the DVLA. The situation is not different in Ghana; vehicles which are stolen sometimes are carried outside the country for resale or reregistered at the DVLA of Ghana. According to a (Customs and Excise Preventive Service (CEPS) post by The Spectator (2008), when a vehicle is detected stolen at the ports and the owner is identified to be resident in a foreign country, the owner is made to bear the cost of returning the vehicle. However stolen vehicles whose owners could not be traced are confiscated and given to the state after which they disposed off accordingly. The information is however silent on what happens to those who stole the vehicles?

The Motto Transport and Traffic Directorate (MTTD) of the Ghana Police Service (GPS) is a governmental institution whose main objective among others is "to prevent and detect motor crimes and offences" as appeared in (ghanapolice.info, n.d.).

Vehicle theft is a crime which cannot be solely handled by the security agencies especially the Ghana Police Service (GPS), but through collaborative effort with individuals and stakeholders. It is in the light of this that the GPS in 1958 became a member of Interpol. And by 1976 Ghana became the first African country to host the Interpol General Assembly (Interpol.int, n.d.). In addition, the GPS has been actively cooperating with police services within and outside the sub-region in the fight against trans-national crimes such as drug trafficking, human trafficking, terrorism, internet fraud, stolen vehicles, trafficking in small arms and light weapons and money laundering (ghanapolice.info, n.d.). Prioritizing vehicle crime, The Interpol General Secretariat has developed a system called an Automated Search Facility-Stolen Motor Vehicle (ASF-SMV) database to support police in member countries in the fight against international vehicle theft and trafficking. According to Interpol (2013), close to 152 countries use this database and in 2010 more than 34,000 motor vehicles were reported to have been discovered worldwide through the ASF-SMV database. Also, statistics indicate that there has been a steady increase in the use of INTERPOL SMV database by member countries both in terms of number of records contributed and the number of searches carried out (Interpol.int, n.d.).

In the local front, the Ghana Police Service relies solely on the DVLA database for their information on registered licenses. The 
DVLA has a number of mandates which include maintaining registers containing particulars of licensed motor vehicles, driving instructors, driving schools and drivers of motor vehicles. Thus, the DVLA is constantly striving to live up to expectation. Currently, the DVLA is making efforts to include a feature on their website for the checking of license status online (dvlaghana.gov.gh, n.d.). Even though very difficult, efforts are being made from time to time by CEPS to bring to book all vehicles which are not duly registered. With all these measures in place, this research revealed, there still exists massive evasion of all kinds of licenses at the DVLA.

Since the first indicator of validation of a registered vehicles is its number plate, a gaping opportunity for car snatchers is created in a situation where a fake number plate go undetected. It is therefore convincing that, there are a large number of vehicles which are using fake number plates. Checking the veracity of a vehicle number is also a very slow system for the law enforcement agencies that have no means of instantly checking vehicle details. Similarly, the veracity of driver licenses is difficult to ascertain since there is no readily available database.

The availability of a centralized database easily accessible to the police even on mobile devices can help to reduce and fight crime in this area. This is the main motivation for this research.

\section{OBJECTIVES OF THE RESEARCH}

The research proposes a model GSM/SMS (Global System for Mobile communication/Short Message Service) technology that can access the DVLA register to boost the work of security services in their zeal to combat vehicle related crime. The specific objectives;

- $\quad$ Explore the possibility and sustainability of integrating SMS technology with DVLA database

- To make the DVLA register easily accessible by security personnel

- To recommend a suitable technology for implementing the recommendations of the research

\section{EXISTING SYSTEM OVERVIEW}

Traditionally, preventing car theft is by the use of immobilizer keys, which was first introduced by Honda in the year 1997. It subsequently became mandatory in all new cars sold, the earliest was in Germany in January 11998 and the latest was in Canada in the year 2007. Early models of immobilizer keys made use of a static code in the ignition key which can be recognized by an RFID (Radio Frequency Identification) loop around the lock barrel and compared with that of the vehicle's Engine Control Unit (ECU) for a match. When the code cannot be recognized, the ECU will stop fuel from flowing and ignition cannot take place (Tech-Spot, 2007). But according to Copes et al (2006) as cited in Tahir and Tahir (2008), there has been an evident increase in the number of vehicles being stolen due to key theft. Vehicle keys have been taken away from their owners by burglary, robbery or without their consent, thus making the use of immobilizer keys as a security measure less effective, because after getting hold of the key an intruder will be able to drive away the vehicle without any obstruction.

Cahoon (2006) drew the attention to the use of a portable memory device in place of a key. According to a US Patent 7006914 as cited in Tahir and Tahir (2008) a portable memory device can be used in place of a key for the following purpose: "A portable memory device used in substitution of an automobile key and interfaced with an automobile onboard computer and ignition system. The portable memory device contains data that, when read by the onboard computer, enables the ignition system."

It can be noted that the portable memory device introduced by Cahoon (2006) does not completely remove the use of a key, but that it is an alternative to the use of a key. To this end the problems associated with the use of the key do also apply to that of the portable memory as well.

In addition, Song (1993) in his U.S Patent Number 5208756 came out with a system in this same direction. In his system, a small hidden device placed in the vehicle is activated through Dual Tone Multi Frequency (DTMF) signals which are transmitted from any telephone station. When the activation is done, the device then determines the power at which normally transmitted control channels are received from the several base stations of the network. Based upon these determinations, the location of the vehicle in respect of the separate distances from each of the base stations is then determined based on calculations, using triangulation. The information about the location of the vehicle is then transmitted through a voice synthesizer back to the telephone station from which the activation signal is received. The location information is also transmitted digitally to a central station where the position of the vehicle is displayed on a computer screen along with a graphical representation of a map of the region served by the cellular telephone network.

More on the application of cellular network, Sheffer and Thompson (1993) designed a system which makes it possible for an emergency message transmission to a remote monitoring station in the event a theft sensor is activated on the vehicle. The monitoring system then detects the cell site identification codes from adjacent cellular transmitter and provides a message including the vehicle identification, cell site identification and signal RSSI (Received Signal Strength Indication). Then based on this information received, a centralized stationed computer then determines the location of the stolen vehicle.

Taking a critical look at the inventions of Sheffer and Thompson (1993) as well as that of Song (1993), it could be noted that, there is a great reliance on a centralized computer for the determination of the location of the stolen vehicle. This ideally will work perfectly if the stolen vehicle is immobile and at the same time not out of coverage area of the cellular network. Because, at the time the location of the vehicle is being tracked, if the arrest team leaves the centralized computer towards where the stolen vehicle is located, and it moves away from such location, you could imagine how difficult it would be to continuously recommunicating this information from the centralized computer to the team.

Following the same suit, Sheffer $(1990,1991)$, in his U.S Patent Numbers 5055851 and 4891650 also made use of cellular network. In both systems, the stolen vehicle sends an identification code and RSSI level to the closest cell site. The active cell site which receives the information reports the theft to 
the cellular Mobile Telephone Switching Office (MTSO) and the MTSO transmits the information to an alarm station which identifies the vehicle and the cell site as well.

The problem associated with the above-mentioned systems are that in most instances, cell sites located in metropolitan areas made use of low-powered $120^{\circ}$ directional antennas to cover a densely populated and developed area which may have a large number of buildings, highways, parking lots, garages and other facilities which make it possible for the thief to hide the vehicle. Thus, although systems may be able to locate the general location of the vehicle with respect to a cell site antenna, the probability of locating the vehicle in the shortest possible time is very small and mostly based on luck.

Furthermore, cell sites located in urban areas cover very large areas with high-powered, Omni-directional antennas, this makes finding the location even more difficult since the antennas are Omni-directional as opposed to being sectioned. In either case, buildings, underground parking lots, mountains and other obstacles may cause the towers to report false RSSI (Received Signal Strength Identification) readings to the MTSO (Mobile Telephone Switching Service).

Another problem that can be seen is the reluctance of the cellular service providers to allow their cellular infrastructure system to be integrated with a foreign application due to security reasons. Since this will be exposing their infrastructure software to externals who might leak information to their competitors.

A need therefore exists for providing a vehicle tracking method and system using the existing cellular network infrastructure which can overcome the problems associated with the prior art. Thus, Savoie and Boulay (1999) designed a system with the necessary incorporations. In this system, a cellular transceiver is installed in vehicles. This transceiver continuously operates but on a standby mode which makes it easily accessible to the cellular security provider, and when tracking of a vehicle is initiated, then the transceiver is turned to active mode. The location of the stolen vehicle is determined by paging the cellular transceiver located in the stolen vehicle. A tracking vehicle making use of radio direction finder then receives the information and obtains an accurate bearing on the location of the stolen vehicle. Alternatively, the tracking vehicle with the radio direction finder can determine the location with respect to one or more cell sites using global positioning system receiver. The tracking vehicle can then quickly move to the identified area.

Taking a critical look at the invention of Savoie and Boulay (1999), there is a great job done by having to dedicate a tracking vehicle which will move to the location of the stolen vehicle. But what then happens when the number of stolen vehicles at one particular time interval exceeds one, it then becomes very difficult to implement.

Again the problem of exact position of the vehicle is not still removed, since the tracking of the vehicle is still based on the availability of signal from the network provider. But when the vehicle is probably driven to an underground tunnel or apartment for dismantling, it thus becomes virtually impossible to locate such a stolen vehicle.

Taking advantage of GSM technology and with the proliferation of cellular phones Drori et al (1992) being so innovative took a right direction to integrate vehicle security with that of cellular phones. In his patent on "system for integrating a cellular www.ijsea.com telephone with a vehicle security system" they described hardware and software for integrating the controller to the vehicle as well as that of the vehicle security to the controller. This system has a feature that allows the vehicle owner to telephone it when he discovers that it has been stolen, thus stopping the engine of the car. Then at certain intervals the coordinates identifying the vehicle location are repeatedly transmitted over the communication system. Making it conveniently possible, to trace for the location of the missing car, especially, at areas with good landmark or street demarcations.

In the situation of Ghana with no effective street names and addresses, the implementation of such a system will not be very effective. Moreover, a thief could easily disable the cellular telephone from the vehicle which will automatically make the security system dump.

Still taking GSM to a different angle, Ruchita et al (2008) came out innovatively. In their research on GSM based car security system, it was made possible for the security system to be alert, such that, the moment the system senses that the car is being stolen, a SMS is immediately sent to the owner's mobile through a GSM modem. At the same time an alert in the form of an alarm blows drawing the attention of nearby people. In this security system it is made possible to sense five parameters for security which include; Vibration sensing, Obstacle sensing, Revolution sensing, Micro switches (where door1 and door2 open) and Battery sensing. When the system detects anything in at least one of the five sensing points it generate sound as well as send SMS through a GSM modem to the owner's phone. Their research made use of a low cost and highly reliable Microcontroller AT89S52 in their system. There is also the incorporation of a buzzer in the system which is responsible for the sound when one of the five parameters is sensed. They came to a conclusion that, this type of system is more advantageous than the simple car security system, since it gives real time information as well as gives alert to nearby people.

While acknowledging the great work of this research, the following observations could be made: The car cannot be safe if the GSM modem is not in working condition or the network for that particular operator is down.

With a lot of shortfalls which seem to have arisen from the preceding inventions, Tahir and Tahir (2008) saw the need for a multifactor authentication mechanism that can easily be embedded into vehicles and which will prevent all sorts of car theft. Their proposed scheme called BioFIM (Biometric Flash Identification Module) was designed and could recognize its owner by the use of features like a combination of fingerprints, portable flash drive and digital certificates. Because of the use of features which are personal to the owner, an overall conclusion was drawn from their research that, this scheme was more resilient against car theft than the existing schemes in terms of security and user convenience.

But on the contrary it could be realized that just as the immobilizer keys, it is only for a matter of time. Criminals will be able to make discoveries into all possibilities of disarming such a security system since in the first place it is embedded into the vehicle itself. 
Still on finding solutions to vehicle security, Zhang et al (2005) gave it a little twist. In their research conducted in the area of vehicle location tracking and monitoring based on GPRS (General Package Radio Services) technology in 2005, Zhang et al (2005) analyzed the shortcomings in traditional vehicle communication systems, their paper presented an intelligent vehicle monitoring system and described the design procedure of hardware and software in details. They compared the two data transmission protocols in GPRS network; their paper then gave a consideration to (User Datagram Protocol) UDP/IP as the vehicle communication protocol.

In a similar fashion, Tan (2010) proposed a Vehicle Monitoring System that would be a high technology system including a sophisticated integration of Geographical Information System (GIS), Global Positioning System (GPS) and other modern communications technologies. Tan's Vehicle Monitoring System would monitor vehicles' accurate positioning, with the aid of communication technology and digital maps. The paper introduced the composition, the operating principle, the overall functions and system structure of vehicle monitoring system.

Referring to both Tan and Zhang et al, there is a reliance on GPRS for the transmission of data. There is a challenge in this direction considering the frequency of power cuts, which is the main source of energy for our telecommunication radios.

\section{SYSTEM OVERVIEW}

The purpose of the system is to provide easy, convenient and on the spot verification of vehicle license and its related information to the security personnel.

In this system a Security Person can send SMS to the SMS gateway server. The server then converts this into an HTTP request and sends to the web application and then receives an HTTP response, and subsequently converts it back to an SMS message and then relays it back to the Security Personnel. The overview can be illustrated in figure 1 .

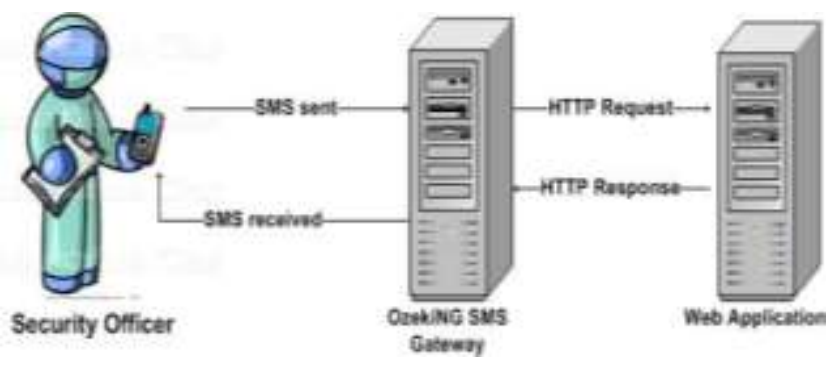

Figure 1. System Overview

\subsection{CONCEPTUAL FRAMEWORK OF THE SYSTEM}

The system is a web application that is built in accordance with the Web Application Framework (WAF), using the Model-ViewController architectural pattern. This model allows for division of any software application into three interconnected parts, so as to separate internal information representation from how it is presented in an acceptable way to the user. Thus, the system consists of three main components, which are controlled and hosted by the web application server, the SMS gateway server and the Database server.

The web application is at the core of the application, carrying out all processing that take place in the system. The web application was built using HTML and CSS for the user interface design and PHP and Java script which carried out all the necessary queries including the request and response queries. The application database was built and managed by MYSQL. This database is interfaced with the web application and maintains all the data from the web user. Taking into consideration how robust the system needs to be, the web application was as well interfaced with an OzekiMessageServer_6.4.1.0. Ozeki Message Server is a powerful and flexible SMS Gateway application which enabled sending and receiving of the SMS messages to and from the mobile user. The interfacing of the web application to that of the OzekiMessageServer was done using the OzekiNG-SMSGateway_4.3.3 which gave it the full ability to communicate with the GSM Modem or Phone that will be connected to it.

The Web User will be a staff of the DVLA who will have login credentials to the system. He will be responsible for making new registration entries as well as making updates to the database. $\mathrm{He}$ will interact with the system using the web interface. Entries made are saved into the Application database and can be viewed as well.

The SMS User represents the personnel from the security services like the Ghana Police. They will be provided with the mobile number of the application's GSM modem/phone. This user can send an SMS to the mobile number of the application using any mobile phone, the registration number, the chassis number or a combination of the two that needs to be instantly verified for its ownership. This text message is received by the SMS gateway server and relayed to the web application. The web application therefore stores this into the tbrequest table in the application database and at the same time searches in the database for related information to the text received. It therefore stores this found information into the tbresponse table in the database as well as retrieves it and returns it to the SMS gateway server. The SMS gateway server then forwards this message back to the SMS user.

The architectural design of the system illustrated in Figure 2 and Figure 3 represents the database entity relationship diagram 


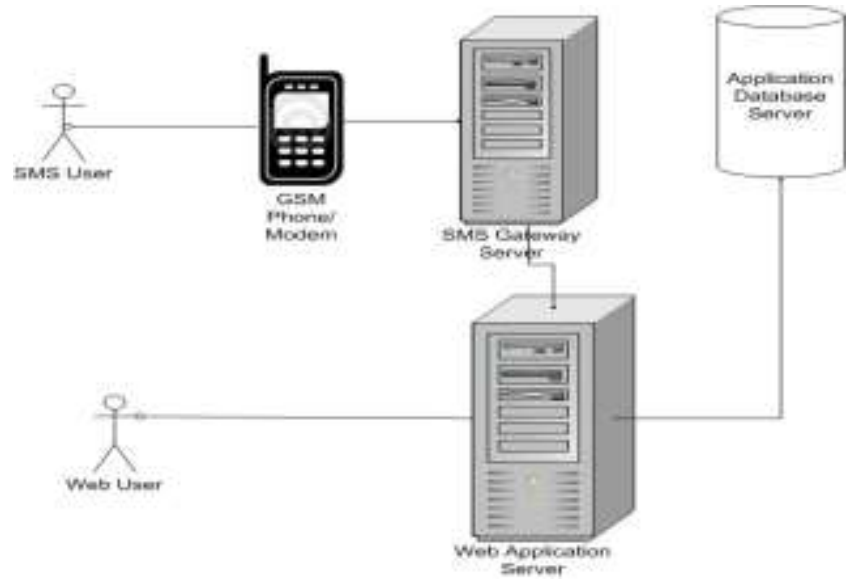

Figure 2. Architecture of the System

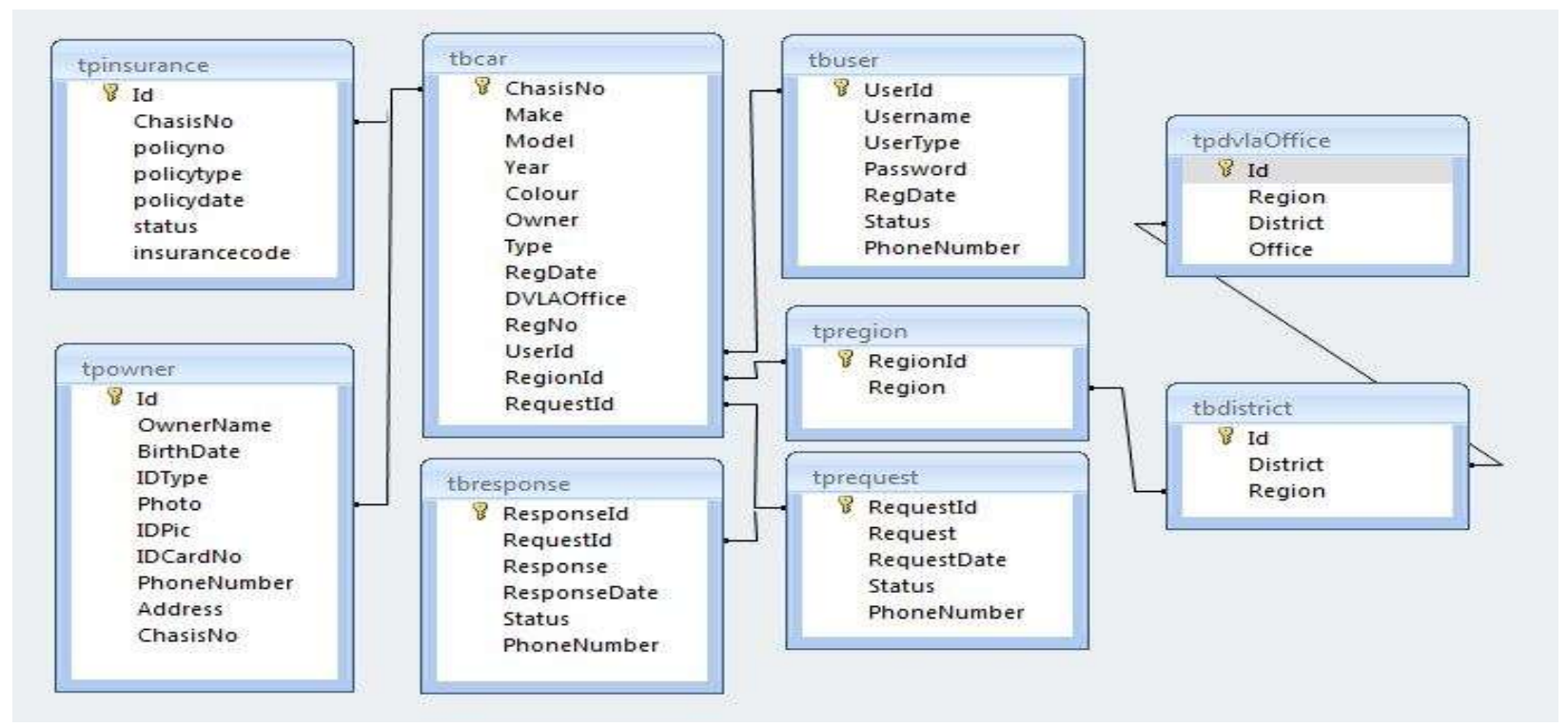

Figure 3. The Entity Relationship Diagram

\section{RESULTS AND DISCUSSIONS}

The results were obtained after interviews and questionnaires were gathered from a population size of 152 (individuals with the distribution of 7 coming from the DVLA staff which covered all management and representation from all sections. 45 from officials of the MTTD of the Ghana Police Service, both private and commercial vehicle owners being 50 , and both private and commercial vehicle drivers taking a population size of 50 . The sample distribution was decided by the researcher and largely influenced by the various respective technical people from DVLA, and MTTD of the Ghana police Service and from leaders of commercial drivers association all within the Metropolis of Tamale.

\subsection{Vehicle theft}

This was a core issue which was critically interrogated, and thus run throughout all the three categories of questionnaires. A large

www.ijsea.com number of respondents attested to the knowledge of the existence of vehicle theft. When the question of "how rampant is the issue of vehicle theft?" was posed, with a total of 139 respondents, only 12 representing 8.6 percent denied the existence of the menace while 127 respondents representing 91.4 percent agreed to the existence of vehicle theft, but had different variation to its frequency as shown in Table 1.

\section{Table 1. Vehicle Theft Occurrence}

\begin{tabular}{|c|c|c|}
\hline Occurrence & Frequency & Percent \\
\hline Daily & 40 & 28.8 \\
\hline Weekly & 9 & 6.5 \\
\hline Occasionally & 78 & 56.1 \\
\hline non-existent & 12 & 8.6 \\
\hline Total & $\mathbf{1 3 9}$ & $\mathbf{1 0 0 . 0}$ \\
\hline
\end{tabular}

It was realized that with the modes of vehicle theft, vehicle snatching came on top with a frequency of 47 representing 49.5 
percent of a total of 95 respondents. Other modes according to the survey and their frequency of occurrence can as well be seen in the bar chart on Figure 4. This was gathered from both drivers and vehicle owners.

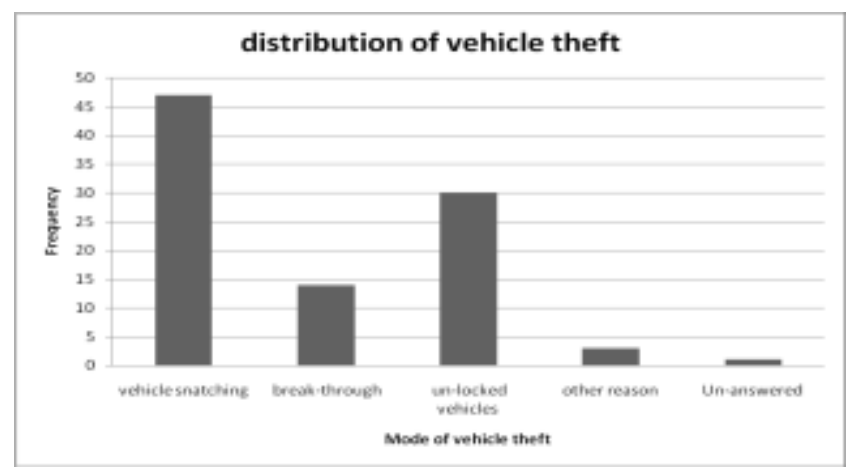

Figure 4. Modes of vehicle theft

\subsection{DVLA and GPS Collaboration}

It became clear from the survey that the GPS and the DVLA do collaborate, but when asked whether the DVLA had given access to their database to the GPS and other security services. Out of 6 respondents 5 indicated no with the remaining 1 declining to answer as seen in Table 2 .

Table 2. Access to DVLA register by Ghana Police Service

\begin{tabular}{|c|c|c|}
\hline Response & Frequency & Percent \\
\hline No & 5 & 83.3 \\
\hline Unanswered & 1 & 16.7 \\
\hline Total & $\mathbf{6}$ & $\mathbf{1 0 0 . 0}$ \\
\hline
\end{tabular}

But when both the DVLA and the GPS were confronted to find out if there is any law against making the DVLA register accessible to the GPS, an overwhelming majority denied the existence of such a law. With a total of 44 respondents, 56.8 percent said there is no such law. The next highest percentage of about 25 of the respondents was not quite sure of such a law against the access as seen in Figure 5.

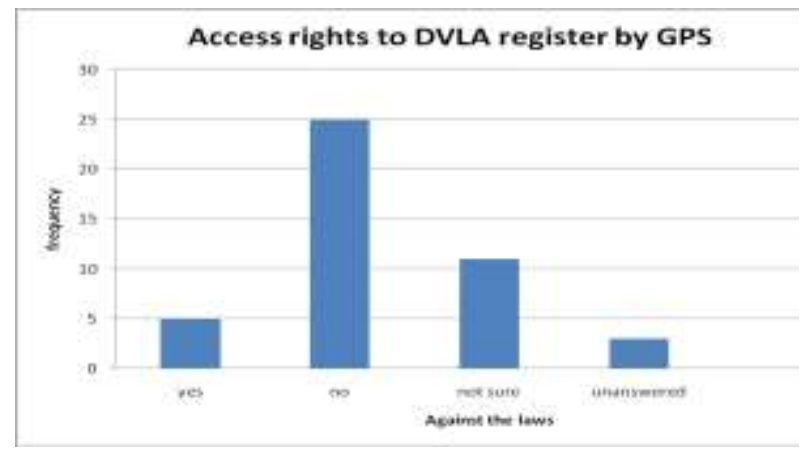

Figure 5. Legal Implications to Gain Access to DVLA Register by GPS

Taking lessons from the above results, one cannot deny the fact that vehicle security does need a great attention. It is therefore very relevant, prudent and timely to have undertaken this research to address the situation of vehicle security. This will give them a good collaboration to help combat vehicle theft

\subsection{Technology Integration and Instant Verification}

From the research it is noted that 82.1 percent of 95 respondents constituting vehicle owners and drivers agree to be charged a fee for the integration of the technology as in figure

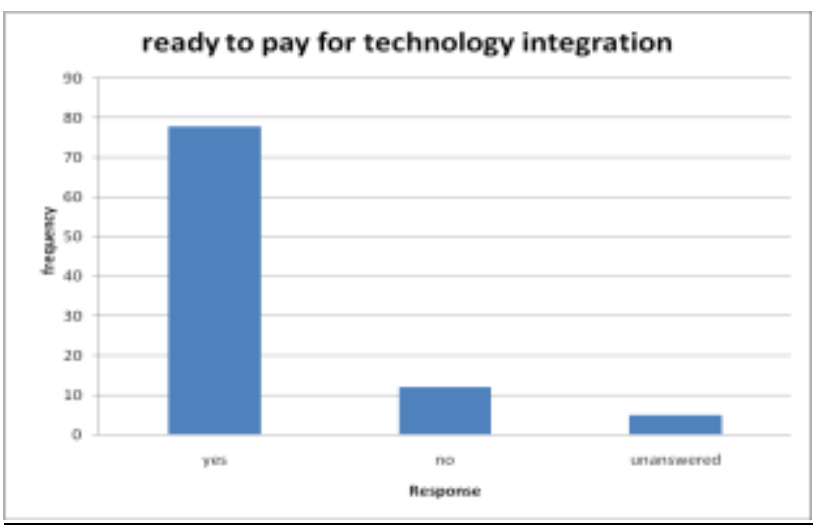

Figure 6. vehicle owners readyness to pay for technology

Still probing further, the researcher sought to know if even vehicle verification will be embraced by all. This was a welcome idea; a total of 125 respondents out of 139 representing 89.9 percent endorsed the idea, this is shown in Table 3. But as to how this should be done, an overwhelming majority indicated it should be by the use of a technology.

Table 3. The Necessity of Instant License Verification

\begin{tabular}{|c|c|c|}
\hline Response & Frequency & Percent \\
\hline Yes & 125 & 89.9 \\
\hline No & 14 & 10.1 \\
\hline Total & $\mathbf{1 3 9}$ & $\mathbf{1 0 0 . 0}$ \\
\hline
\end{tabular}

When they were further confronted with, which technology will be appropriate and convenient? There were interesting responses. Bio-metric verification came on top with a percentage of 68.3 of a total of 139 respondents. This left SMS verification behind with a percentage of 27.3 of the respondents. Insignificantly was the response for the use of phone call or the internet for verification as seen in Figure 7. 


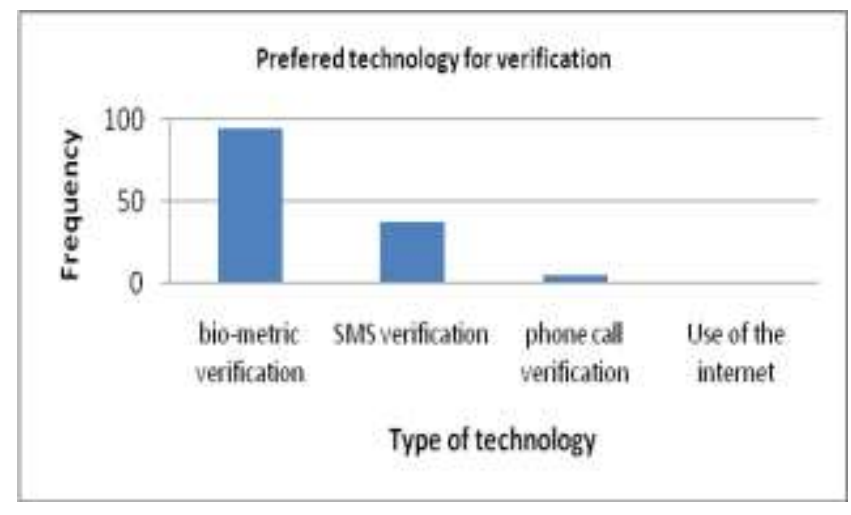

Figure 7. Technology of choice for license verification

Taking a critical look at the responses in Figure 7 and the possible influence on arriving at the bio-metric verification, it is evident that GSM/SMS technology has not been exploited to its maximum. Those respondents probably did not know what SMS referred or have not yet been exposed to the applications of SMS.

\subsection{System Implementation and Output}

When the system was implemented an SMS message like "hh22222" was sent to the system, this saw a reply as shown in Figure 8. While an SMS message like "Hi" on the other hand had a reply as in Figure 9.

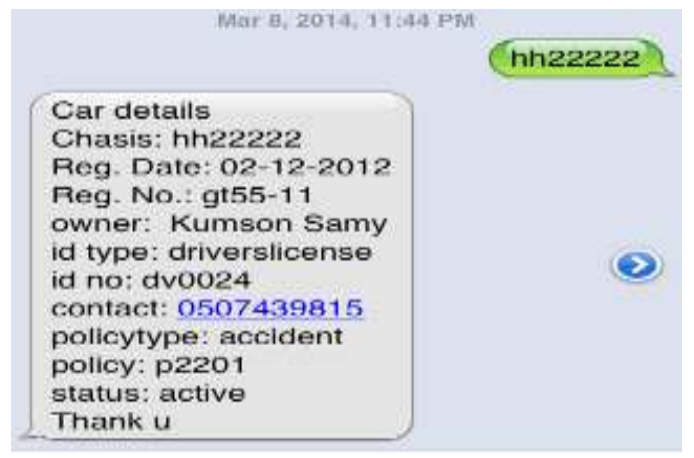

Figure 8. Sample reply with existing details

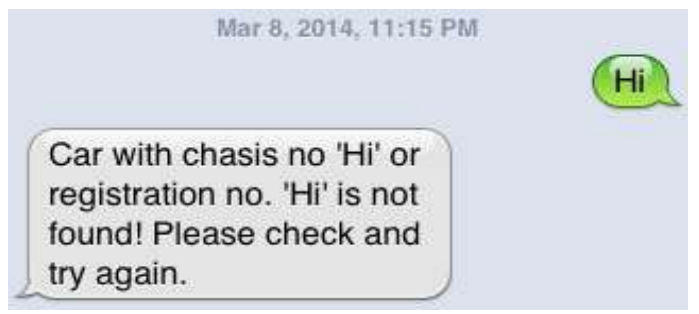

Figure 9. Sample reply for non-existence

\section{CONCLUSION AND FUTURE WORK}

It became clear from the results that the security of vehicle is of great concern. Thus, instant verification of licenses by the use of a technology was a necessity. The recommended technology for carrying out this verification is the bio-metric with SMS placing second.

There should be in the future a need to design an algorithm which will enable a police man to send the chassis number of a reported stolen vehicle to the database to alert all stakeholders of the said case.

There should be an investigation into the possibilities of integrating bio-metric verification into the current system and a possible implementation of the said technology.

\section{REFERENCES}

[1] C.P. Cahoon (2006) Portable memory automobile ignition System “U.S. Patent 7006914", p.2

[2] Celestine Bassey and O. O. Oshita (c2010), Governance and Border Security in Africa Malthouse Press Limited, 43 Onitana Street Lagos @2010 ISBN 9789788422075

[3] Copes, Heith and Cherbonneau, Michael (2006) The Key to Auto Theft: Emerging Methods of Auto Theft from the Offenders' Perspective. The British Journal of Criminology, Vol. 46, Issue 5, pp. 917-934, 2006

[4] DVLAGHANA.GOV.GH(n.d.) Available from: http://dvlaghana.gov.gh/pub/?pid=43\&rlid=2 [Accessed 30/07/12

[5] Eliezer A. Sheffer (1990). Vehicle Location System U.S. Pat. No. 4,891,650,p.1

[6] Eliezer A. Sheffer (1991). Vehicle Location System U.S. Pat. No. $5,055,851$, p. 2

[7] Eliezer A. Sheffer, Marco J. Thompson (1993). Vehicle Tracking System U.S. Pat. No. 5,218,367, p.2

[8] GHANAPOLICE.INFO (n.d) Available from: http://www.ghanapolice.info/mttu/functions.htm [Accessed 07/02/13]

[9] GHANAPOLICE.INFO (n.d.) Available from: http://www.ghanapolice.info/forensi c_lab.htm

[10] Han L. Song (1993). Vehicle Location and Navigation System U.S. Pat. No. 5,208,756, p.1

[11] Hasan Tahir and Ruhma Tahir (2008) BioFIM: Multifactor Authentication for Defeating Vehicle Theft, Proceedings of the World Congress on Engineering Vol I WCE 2008, London, U.K, pp.1-3

[12] Hui Tan (2010) Design and Implementation of Vehicle Monitoring System Based on GSM/GIS/GPS, Information Technology and Computer Science (ITCS), 2010 Second International Conference on, vol., no., pp.413-416 
International Journal of Science and Engineering Applications

Volume 4 Issue 5,2015, ISSN 2319-7560 (Online)

[13] INTERPOL.INT (n.d.) Database Statistics. Available from: http://www.interpol.int/ crime/Database-statistics[Accessed 02/02/13]

[14] INTERPOL.INT(n.d.) Available from: https://secure.interpol.int/Public/Vehicle/Default.asp

[15] OSAC.GOV (2011) Ghana 2011 OSAC Crime and Safety Report. Available from: https://www.osac.gov/Pages/ContentReportPDF.aspx?cid=10 792 [Accessed 23/03/13]

[16] Paul-Andre Roland Savoie, Andre Eric Boulay (1999) Vehicle Tracking System Using Cellular Network U.S. Pat. No. $5,895,436$, p.3

[17] Peng-Chao Zhang; Zhong-Ke Shi; Meng Xu (2005) Design and implementation of vehicle monitoring system based on GPRS, Machine Learning and Cybernetics, 2005.
Proceedings of 2005 International Conference, vol.6, no., pp.3574-3578 Vol. 6, p.3, 18-21 Aug. 2005

[18] Ruchita J. Shah, Anuradha P. Gharge (2008) GSM based car security system, International Journal of Engineering and Innovative Technology (IJEIT) Volume 2, Issue 4, p.5, October 2012

[19] TECH-SPOT: HONDA'S HISS (2007) Available from: http://ww1.honda.co.uk/news/motorcycles/20070308.html

[20] THE SPECTATOR (2008) 70,000 cars imported into Ghana yearly. Available from: http://www.modernghana.com/news/162413/1/70000-carsimported-into-ghana-yearly.html [Accessed 02/02/13]

[21] Ze'ev Drori, Robert M. Woskow, Encino (1992) system for integrating a cellular telephone with a vehicle security system US, pat. US005081667A, p.2 